\title{
Recent Development on Transition-Metal Catalysts for Olefin Polymerizations
}

\author{
H. L. HSIEH \\ Research and Development, Phillips Petroleum Company, \\ Bartlesville, Oklahoma 74004, U.S.A.
}

(Received April 15, 1980)

\begin{abstract}
Current processes and state of art of olefin polymerizations are briefly reviewed. Several high-activity transition-metal olefin polymerization catalysts developed by Phillips Petroleum Company are reported and discussed.

KEY WORDS Ethylene / Propylene / Polymerization / Catalyst / Process /

Transition Metal / Titanium / Vanadium / Magnesium /
\end{abstract}

Before discussing individual catalysts, it will be necessary to briefly describe our current processes and state of art. At present, there are three basic types of olefin-polymerization processes: (1) slurry, (2) solution, and (3) gas phase. We employ commercially both slurry and solution reactions (Table I). The slurry process uses an inert hydrocarbon such as isobutane or a monomer such as propylene. In this process, the reactors are operated at temperatures below the temperature at which the polymer produced begins to dissolve in the hydrocarbon. The solution process operates at higher temperatures so that the polymer dissolves in the hydrocarbon diluent as it is being formed.

Table I. Phillips olefin polymerization processes
A. Slurry (below solution temperature)
1. Polypropylene (propylene)
2. Polyethylene (isobutane)
B. Solution (above solution temperature)
1. Polyethylene (cyclohexane)

Phillips commercially uses the slurry process with propylene as the diluent for production of polypropylene resins. The solid polymer is separated in a washing step from the amorphous materials which are soluble in propylene. During the wash process, catalyst residues are also removed from the polymer.
For polyethylene production, both the slurry and solution processes are employed. One catalyst used in either of these processes is chromium oxide supported on silica. Unlike many processes using Ziegler-Natta catalysts, productivities are so high that no catalyst removal steps are required. The polyethylene fluff, as it comes from the reactor is simply dried and pelletized. Nearly one half of all high-density polyethylene produced in the world today is made with the Phillips developed slurry process utilizing loop reactors. The solution process costs more in terms of energy to operate; it is used only for the production of a few premium resins which are difficult to produce in the slurry process.

The polyolefin industry is a highly competitive one and one which requires continuous innovations to stay abreast of it. Phillips is committed to this and has a highly active, on-going research program to improve process, catalyst and finishing techniques. My comments today will be restricted to the area of catalysts. In polypropylene, the industry is actively seeking methods of eliminating liquid propylene soluble polymer. We feel the Phillips process for polypropylene, which is a second generation process, now produces some of the lowest propylene solubles that can be found in the industry, but even lowering these solubles an additional one percent can mean a significant savings in cost. In conjunction with reduced solubles, Montedison and others' are continuing to increase productivities per unit of time in order to 
eliminate completely any washing of the resin produced. It should be emphasized that increased productivities are of no use unless soluble polymer is decreased or remains constant. The biggest savings in cost due to increased productivities do not occur in current operation but in the construction of new plants where wash columns and associated equipment can be eliminated.

In polyethylene, the industry is continuing to explore catalysts which will control melt indices over an even broader range. We have had recent success in this goal with chromium oxide catalysts but I will restrict my comments to the high-activity transition-metal catalysts. In today's state of the art, molecular-weight distribution of polyethylenes is playing an ever increasing role and we are striving to develop catalyst systems which will allow us to tailor polymers with the desired molecular-weight distribution. Another area of intense activity within the polyethylene industry is copolymers. Here, more efficient utilization of comonomers and beter polymer properties at lower and lower densities are sought. (see Table II).

Table II. Areas of catalyst research
A. Polypropylene
1. Lower propylene solubles
2. Increased productivities
B. Polyethylene
1. Molecular-weight distribution control
2. Copolymers
3. High productivities

What constitutes a "new Phillips" catalyst? Ordinarily this question would seem directed at chromium oxide catalysts, but for the past several years we have been actively exploring all possible avenues of research in order to take advantage of the unique features of each potential catalyst. Today my remarks will be addressed at only that portion of our research dealing with highly-active transitionmetal catalysts excluding all chromium oxide developments.

The phrase, "high-activity catalyst," in regards to transition-metal olefin polymerization catalysts has been abused and often times misused in recent years. The patent literature is full of examples of highactivity catalysts when all that is meant is a high yield of polymer per unit weight of titanium. In many of these instances other catalyst components such as chloride ions are exceedingly high in the polymer, or the polymerization times and conditions are not commercially feasible. Thus one must be cautious when dealing with published productivity values.

As an example, we investigated one catalyst system which yielded $3.3 \times 10^{6}$ grams of polyethylene per gram of titanium. However, there were other catalyst components to be considered. As it turned out, productivity based on total catalyst was only 2000 grams per gram which is not commercially acceptable.

By a highly-active catalyst we mean one which leaves no more than $10 \mathrm{ppm}$ titanium and $30 \mathrm{ppm}$ chloride in the polymer formed. Titanium levels higher than this can lead to color problems, and higher chloride content can result in excessive corrosion problems. In addition, other metals must be present in less than $10 \mathrm{ppm}$ in the polymer with the actual permissible level controlled on an individual basis. Any residues in the polymer must meet FDA regulations.

The advantages of highly-active catalysts have been greatly overstated in recent years. In fact only through activities high enough to eliminate catalyst removal is it possible for transition-metal catalysts to compete with chromium oxide catalysts where catalyst removal is not used. In addition the chromium oxide system contains no chloride. Therefore, the use of high-activity transition-metal catalysts to replace chromium oxide systems cannot be justified solely in terms of productivity. A similar situation is found for polypropylene. Here the new catalyst must be so high in productivity and stereofecificity that all postpolymerization purification steps are eliminated and the catalyst must be relatively inexpensive as "installed" purification systems are not exceedingly expensive to operate. The main cost savings would not be in existing plants but in newly constructed facilities.

Although high activities are a must for any new transition-metal catalyst, the main advantages are to be found in other areas. We are continually seeking new and unique polymer properties which will meet customers needs. In this same vein we apply methods of tailoring molecular-weight distributions and improving polymers through appropriate comonomer selection. 
As stated earlier one of the biggest benefits in polypropylene would be complete elimination of amorphous polypropylene. Another common goal of all researchers in the polyolefin area is uniform spherical polymer particles right from the reactor.

With this as background, I will now discuss some of the catalyst systems which we have explored in the past few years.

High-activity transition-metal catalysts are generally prepared by one of two techniques. Either the catalyst is prepared with intensive ball milling or no milling is used at all. One of the first catalysts studied was prepared by milling magnesium chloride and titanium tetrachloride together. The productivity, $\mathrm{kg}$ of polymer/g of catalyst, of the catalyst is determined by the amount of titanium tetrachloride in the catalyst. At low levels, productivities based on titanium are very high while at higher levels productivities based on titanium rapidly decrease. The most important productivity, however, is that based on total catalyst so that chloride residuals are at a minimum. The typical catalyst might contain $4 \%$ titanium. In pilot plant evaluations this catalyst produced $20 \mathrm{~kg} \mathrm{~g}^{-1} \mathrm{~h}^{-1}$ of polyethylene with a triethylaluminum cocatalyst. At this productivity polymer residue would include $2 \mathrm{ppm}$ titanium and $40 \mathrm{ppm}$ chloride (see Table III).

Table III. Milled $\mathrm{MgCl}_{2}-\mathrm{TiCl}_{4}$ catalyst

$$
10 \mathrm{MgCl}_{2}+\mathrm{TiCl}_{4} \stackrel{\text { Vibratory mill }}{\longrightarrow} 10 \underset{(4 \% \mathrm{Ti})}{\mathrm{MgCl}_{2} \cdot \mathrm{TiCl}_{4}}
$$

Productivity, $20 \mathrm{~kg} \mathrm{~g}^{-1} \mathrm{~h}^{-1}$ with TEA as cocatalyst Polymer residual, $2 \mathrm{ppm} \mathrm{Ti}$ and $40 \mathrm{ppm} \mathrm{Cl}^{-}$

Even more efficient use of the titanium tetrachloride can be made with a catalyst formed by ball milling together a Lewis base, e.g., phenol, and magnesium chloride and treating this solid with titanium tetrachloride. Again productivities were found to be close to $20 \mathrm{~kg} \mathrm{~g}^{-1} \mathrm{~h}^{-1}$ but titanium content was only $1.6 \%$. Therefore, residual titanium and chloride would be $0.8 \mathrm{ppm}$ and $35 \mathrm{ppm}$, respectively (see Table IV). This catalyst has good commercial potential especially in view of the number of Lewis bases that can be employed. Each base imparts its own peculiarities to the catalyst. Productivities vary, comonomer response is different, and molecular-weight distribution can be controlled to a certain extent. The most interesting feature of this catalyst, however, is in the area of propylene polymerization which will be discussed later. One of the oddities of polyolefin research is that some catalysts efficiently polymerize propylene and ethylene while others are fairly specific for one or the other monomer.

Table IV. Milled Lewis base- $\mathrm{MgCl}_{2}-\mathrm{TiCl}_{4}$ catalyst

$$
\begin{aligned}
& \mathrm{MgCl}_{2}+\text { Phenol } \stackrel{\text { Vibratory mill }}{\longrightarrow} \text { Solid A } \\
& \text { Solid A+TiCl } 4 \text { Heptane } \\
& \stackrel{100^{\circ} \mathrm{C}}{\longrightarrow} \text { Catalyst }(1.6 \% \mathrm{Ti})
\end{aligned}
$$

Productivity, $20 \mathrm{~kg} \mathrm{~g}^{-1} \mathrm{~h}^{-1}$ with TEA as cocatalyst Polymer residuals, $0.8 \mathrm{ppm} \mathrm{Ti}$ and $35 \mathrm{ppm} \mathrm{Cl}^{-}$

In general, milled catalysts are somewhat more difficult to prepare than their unmilled counterparts. Milling must be done under anhydrous conditions. This is difficult and expensive especially for the limited quantities of catalyst required due to the high activities. The prefered method would be one in which the catalyst requires no milling. It is much easier to handle a slurry in a closed system, than it is to handle a solid material in a ball mill.

On catalyst system we found which satisfies this requirement is prepared with both titanium and vanadium compounds (see Table V). It is prepared by contacting titanium (IV) ethoxide and vanadium (V) oxytrichloride for several hours to form a red viscous liquid. This liquid is diluted with a hydrocarbon, and ethylaluminum sesquichloride is added which precipitates a brown solid. The brown

Table V. $\mathrm{Ti}(\mathrm{OEt})_{4}-\mathrm{VOCl}_{3}-\mathrm{EASC}-\mathrm{TiCl}_{4}$ catalyst

$$
\begin{aligned}
& \mathrm{Ti}(\mathrm{OEt})_{4}-\mathrm{VOCl}_{3} \frac{\text { Room temp }}{2-3 \text { days }} \mathrm{VOCl}_{3-x}(\mathrm{OR})_{x}+ \\
& \mathrm{Ti}(\mathrm{OR})_{4-x} \mathrm{Cl}_{x} \\
& \quad \text { (Red viscous liquid) }
\end{aligned}
$$

Red liquid +2.4 EASC $\stackrel{\text { Hexane }}{\longrightarrow}$ Brown powder

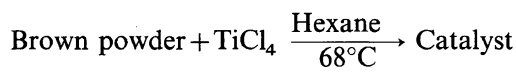

Productivity, $50 \mathrm{~kg} \mathrm{~g}^{-1} \mathrm{~h}^{-1}$ with TEA as cocatalyst Polymer residuals, $\mathrm{Ti}<1 \mathrm{ppm} \mathrm{V}<1 \mathrm{ppm} \mathrm{Cl}^{-}<30 \mathrm{ppm}$ 


\section{H. L. HSIEH}

solid is then treated with titanium (IV) chloride to form the catalyst.

It is probable that a slow exchange reaction occurs to produce $\mathrm{VOCl}_{3-x} \quad(\mathrm{OR})_{x}$ and $\mathrm{Ti}(\mathrm{OR})_{4-x} \mathrm{Cl}_{x}$. The nature of the OR group is extremely important with the highest productivities resulting when $\mathrm{OR}$ is ethoxide (Figure 1). The aluminum to titanium plus vanadium mole ratio is also important. Optimum ratios are around 1.0 for both the catalyst prepared before and after the titanium (IV) chloride treatment (Figure 2). The degree of reduction of the vanadium may be the critical feature involved.

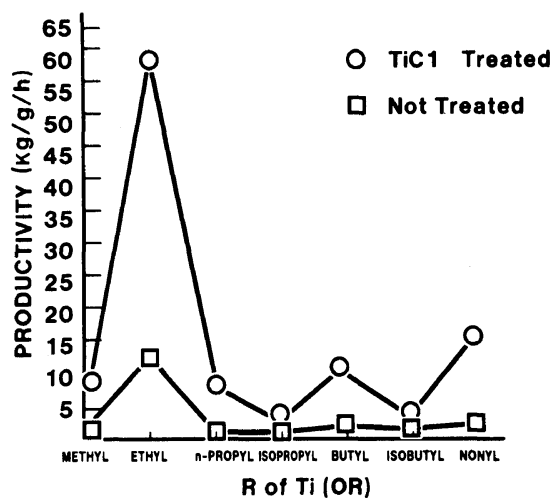

Figure 1. Productivity as a function of the titanium alkoxide.

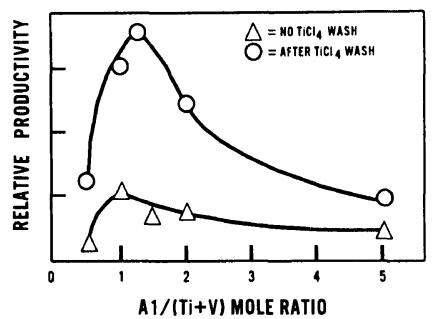

Figure 2. Influence of aluminum (EASC) to transitionmetal ratio on productivity.

The productivity of this catalyst in the pilot plant was as high as $50 \mathrm{~kg} \mathrm{~g}^{-1} \mathrm{~h}^{-1}$ which means titanium and vanadium residues in the polymer are less than $1 \mathrm{ppm}$ and chloride is less than $30 \mathrm{ppm}$ with TEA as the cocatalyst. This is equivalent to or better than any milled catalyst of which we have knowledge. In addition, there are advantages in the form of the fluff produced. The resins produced have an excellent balance of properties when compared to commercial resins (see Table VI). Properties are very similar with superior stiffness, impact strength, and environmental stress-crack resistance. The only limitation found for these resins was the melt fracture observed for blow molding resins which is characteristic of narrow-molecularweight-distribution polymers made with highactivity transition-metal compounds.

Table VI. Comparison of resins made with conventional chromium silica and $\mathrm{Ti}(\mathrm{OEt})_{4}-\mathrm{VOCl}_{3}-\mathrm{EASC}-\mathrm{TiCl}_{4}$ catalysts

\begin{tabular}{lllll}
\hline \multicolumn{1}{c}{ Catalyst } & $\begin{array}{c}\text { Transition } \\
\text { metal }\end{array}$ & $\begin{array}{c}\text { Chromium } \\
\text { silica }\end{array}$ & $\begin{array}{c}\text { Transition } \\
\text { metal }\end{array}$ & $\begin{array}{c}\text { Chromium } \\
\text { silica }\end{array}$ \\
\hline Melt Index & 28.3 & 34 & 20 & 18.3 \\
CIL & 24.6 & 29 & 18.4 & 19.5 \\
CIL/MI & 0.87 & 0.83 & 0.91 & 1.07 \\
Density & 0.970 & 0.968 & 0.956 & 0.955 \\
$\begin{array}{l}\text { Flexural modulus (MPa) } \\
27.9 \text { cm Bowl impact }(\mathrm{J})\end{array}$ & 2240 & 1920 & 1520 & 1370 \\
$\quad 22.8^{\circ} \mathrm{C}$ & 47 & 9.9 & 96 & 83 \\
$\quad-18.0^{\circ} \mathrm{C}$ & 41 & 9.4 & $>81$ & 91 \\
$\begin{array}{l}\text { Warpage (cm) } \\
\quad \text { Max }\end{array}$ & 1.32 & 1.02 & 1.14 & 0.99 \\
$\quad \begin{array}{c}\text { Min } \\
\text { Catalyst productivity } \\
\quad \text { (g PE/g Catalyst) }\end{array}$ & 0.48 & 0.86 & 0.38 & 0.53 \\
$\begin{array}{c}\text { Triethylaluminum } \\
\text { productivity } \\
\text { (g PE/g TEA) }\end{array}$ & 37,000 & 3,000 & 47,000 & 3,000 \\
$\quad$ & & & & \\
$\quad$ & 22,000 & - & 23,000 & - \\
\hline
\end{tabular}


Table VII. Silica-supported $\mathrm{Ti}(\mathrm{OEt})_{4}-\mathrm{VOCl}_{3}-\mathrm{EASC}-\mathrm{TiCl}_{4}$

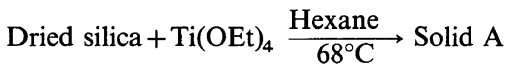

Solid $\mathrm{A}+\mathrm{VOCl}_{3} \stackrel{\text { Hexane }}{\longrightarrow}$ Solid B

Solid B+EASC $\stackrel{\text { Hexane }}{\longrightarrow}$ Solid C

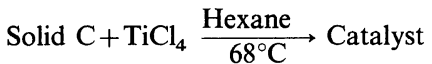

Productivity, $4 \mathrm{~kg} \mathrm{~g}^{-1} \mathrm{~h}^{-1}$ with TEA as cocatalyst

Polymer residuals, $\mathrm{Ti}<10 \mathrm{ppm} \mathrm{V}<10 \mathrm{ppm} \mathrm{Cl}^{-}<50 \mathrm{ppm}$

This catalyst has also been prepared in the presence of a support such as silica (see Table VII). The goal here was to even further improve productivities. This does not happen, however, and one must dry the support material which adds considerable cost to the preparation.

Despite all the advantages found for this catalyst, there are some disadvantages. It does not incorporate comonomers as well as some of the magnesium chloride supported systems, and it responds poorly to hydrogen. Excessive amounts of hydrogen are required to produce high-melt-index polymers. These high levels of hydrogen in turn significantly reduce polymerization activity.

That brings us to polypropylene catalysts. Here again we started by looking at milled systems. One of the first catalysts investigated was one prepared by milling together magnesium chloride, ethyl benzoate, 1-hexene, and titanium tetrachloride. These catalysts are very active during the first few minutes of polymerization. Surprisingly solubles remain essentially constant with time. These catalysts also respond much differently to changes in reactor temperature than do conventional titanium trichloride catalysts (Figure 3). Productivities are maximum at $55^{\circ} \mathrm{C}$, and soluble-polymer formation steadily decreases as temperature is increased. This is unfortunate as one would like maximum activity to coincide with minimum solubles.

Perhaps the most important feature of this catalyst system is the cocatalyst. In addition to the usual aluminum alkyl required for conventional catalysts, these supported catalysts require an additive to suppress soluble-polymer formation. We have had best results using a cocatalyst which contains equal moles of triethylaluminum and

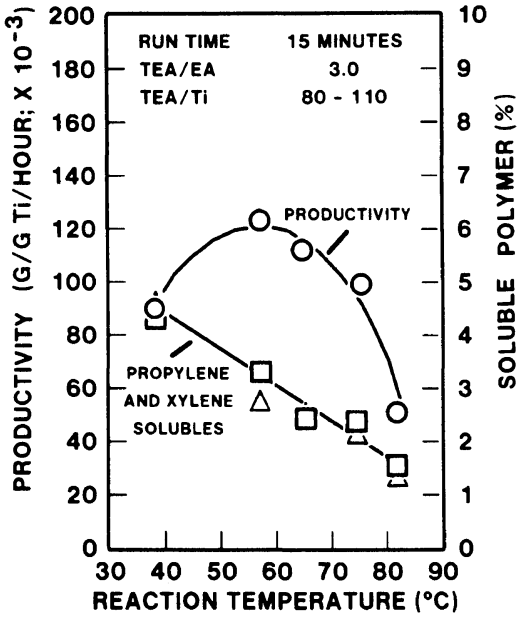

Figure 3. Productivity as a function of reactor temperature (15 minute runs).

Table VIII. $\mathrm{MgCl}_{2}$-ethyl benzoate-1-hexene$\mathrm{TiCl}_{4}$ catalyst

\author{
$\mathrm{MgCl}_{2}+$ Ethyl benzoate $+1-$ Hexene $+\mathrm{TiCl}_{4}$

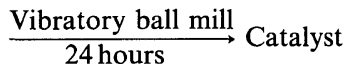 \\ Cocatalyst, TEA-DEAC-ethyl anisate \\ Productivity, $6 \mathrm{~kg} \mathrm{~g}^{-1} \mathrm{~h}^{-1}$ \\ Solubles, $4 \%$ xylene and propylene \\ Polymer residuals, Ti $7 \mathrm{ppm} ; \mathrm{Cl}^{-} 120 \mathrm{ppm}$
}

diethylaluminum chloride with an ester which may be either ethyl anisate or ethyl benzoate (see Table VIII). This combination results in the optimum balance between high activity and low solubles. Pilot plant studies with this catalyst and cocatalyst combination have been disappointing. Productivities of only $6 \mathrm{~kg} \mathrm{~g}^{-1}$ were achieved at relatively high solubles levels. This would mean that titanium and chloride residuals would be 7 and $120 \mathrm{ppm}$, respectively. These levels are not acceptable. Therefore, further improvements are required for this catalyst to have commercial utility.

Simultaneous work was carried out on a catalyst system prepared by reacting magnesium powder, alkyl halide and titanium tetrachloride in an intensive ball mill (see Table IX). The magnesium reacts to form $\mathrm{R}_{2} \mathrm{Mg} \cdot \mathrm{MgCl}_{2}$ which then reacts with titanium tetrahcloride to give a titanium trichloride 
Table IX. $\mathrm{RCl}-\mathrm{Mg}-\mathrm{TiCl}_{4}$ catalyst

$$
\begin{gathered}
\mathrm{RCl}+\mathrm{Mg}+\mathrm{TiCl}_{4} \frac{\text { Vibratory ball mill }}{24 \text { hours }} \text { Catalyst } \\
\text { Cocatlyst, TEA-Ethyl anisate }
\end{gathered}
$$

supported on magnesium chloride. This is a unique method of forming a supported catalyst system which contains Ti (III) instead of the usual Ti (IV) species. High activities are easily obtained with this catalyst, but the amount of amorphous polymer formed is also very high. This means that solublepolymer formation must be controlled as before with appropriate selection of the cocatalyst. The cocatalyst which performs best is that which was just described. Again, however, it has not been possible to maintain high productivities and at the same time reduce solubles to the desired level. In essence this is the one difficulty which has been found for many of the high-activity catalysts.

The catalyst prepared by milling magnesium chloride and a Lewis base together followed by a titanium tetrachloride treatment is a very promising one (see Table $\mathrm{X}$ ). This catalyst makes an excellent propylene polymerization catalyst in addition to ethylene polymerization catalyst as already discussed. The Lewis base used is essential to the success attained. The same cocatalyst, triethylalu-
Table X. Lewis base- $\mathrm{MgCl}_{2}-\mathrm{TiCl}_{4}$ catalyst

$$
\begin{array}{r}
\mathrm{MgCl}_{2}+\text { Phenol } \stackrel{\text { Vibratory mill }}{\longrightarrow} \text { Solid A } \\
\text { Solid } \mathrm{A}+\mathrm{TiCl}_{4} \underset{100^{\circ} \mathrm{C}}{\stackrel{\text { Heptane }}{\longrightarrow}} \text { Catalyst } \\
\text { Productivity, } 14 \mathrm{~kg} \mathrm{~g}^{-1} \mathrm{~h}^{-1}
\end{array}
$$

Solubles, $4 \%$ in xylene and $2 \%$ in propylene Polymer residuals, $\mathrm{Ti}<1 \mathrm{ppm} ; \mathrm{Cl}^{-} 50 \mathrm{ppm}$

minum, diethylaluminum chloride, and ester, was found to work well. With this combination, pilot plant productivities of $14 \mathrm{~kg} \mathrm{~g}^{-1}$ were attained. This means that titanium and chloride levels would be 1 and $50 \mathrm{ppm}$, respectively. The total solubles is still somewhat higher than desired. We are continuing to explore other catalysts both in the laboratory and pilot plant.

The so-called "second generation" olefin polymerization catalysts generated a lot of excitement initially. However, to be a viable commercial alternative to the established catalysts, they will have to demonstrate better polymer properties as well as cost savings. Phillips has been among the leaders in olefin polymerization catalysts and processes and we are committed to maintain this position in the future. 